DOI: $10.15593 / 24111678 / 2016.04 .05$

УДК 625.712 .1

\author{
А.В. Весникова ${ }^{1}$, А.М. Бургонутдинов ${ }^{1}$, П.С. Ожигин ${ }^{2}$ \\ 1 Пермский национальный исследовательский \\ политехнический университет, Пермь, Россия \\ ${ }^{2}$ Пермский военный институт войск национальной гвардии \\ Российской Федерации, Пермь, Россия

\section{ВОЗДЕЙСТВИЕ ОТХОДОВ АСФАЛЬТОГРАНУЛЯТА НА ПОЧВЕННЫЙ ПОКРОВ ПРИ ИХ ВРЕМЕННОМ СКЛАДИРОВАНИИ И ВТОРИЧНОМ ИСПОЛЬЗОВАНИИ}

При строительстве и ремонте автомобильных дорог нельзя забывать о негативном влиянии на окружающую среду. Совсем недавно появилась такая технология, как фрезерование асфальта. Этот способ ремонта автомобильной дороги подразумевает вторичное использование материала старой дорожной одежды. Ассральтогранулят допускается использовать как материал для устройства оснований и нижних слоев покрытия или укрепления обочин. Одним из преимуществ фрезерования является отсутствие затрат на хранение, утилизацию удаляемого асфальта и доставку горячей асфальтобетонной смеси. После фрезерования старого асфальтобетонного покрытия дороги возникает потребность во временном складировании полученного материала, желательно вблизи ремонтируемого участка. Хранящийся в виде насыпи асфальтогранулят на придорожной полосе оказывает негативное влияние на окружающую среду. Из-за атмосферных осадков, поверхностных и грунтовых вод в почву попадают загрязняющие вещества, такие как тяжелые металлы или нефтесодержащие примеси. Происходит полное или частичное уничтожение почвенно-растительного слоя, замечается опустынивание земель. При разгрузке, погрузке и хранении асфральтогранулята в атмосферный воздух попадают пылеобразные загрязняющие вещества. Это нельзя оставлять без внимания, особенно если работы ведутся в городских условиях. В Федеральном классификационном каталоге отходов асфральтовая крошка относится к IV классу отходов (малоопасные). Экологическая система после воздействия на нее асфральтогранулята нарушается, ей потребуется не менее трех лет для самовосстановления. Площадка для складирования должна быть подготовлена с учетом требований для хранения данного материала. Устраиваются водонепроницаемое покрытие, исключающее загрязнение почвы, навес для защиты поверхности насыпи от осадков и ветра и схема водоотведения сточных вод.

Ключевые слова: ремонт дорожного покрытия, технология холодной регенерации, ресайклер, дорожная фреза, асфальтогранулят, дорожно-строительные материалы, складирование, класс опасности отхода, утилизация отходов, экология, почва, загрязнение.

\author{
A.V. Vesnikova1, A.M. Burgonutdinov ${ }^{1}$, P.S. Ozhigin ${ }^{2}$ \\ ${ }^{1}$ Perm National Research Polytechnic University, Perm, Russian Federation \\ ${ }^{2}$ Perm Military Institute of the National Guard troops of the Russian Federation, \\ Perm, Russian Federation
}

\title{
THE IMPACT OF ASPHALTGRANULATE WASTE ON SOIL COVER IN THEIR TEMPORARY STORAGE AND SECONDARY USE
}

In the construction and repair of roads should not forget about the negative impact on the environment. More recently, there was such a technology as asphalt milling. This method of repair of the road 
means recycling existing pavement material. Asfaltogranulate may be used as the material for the base of the device and lower layers of the coating, or strengthening the shoulders. One of the advantages is the absence of cutting storage costs, disposal of the removed asphalt and hot mix delivery. After milling of the old asphalt concrete road cover there is a need in the temporary storage of the resulting material, preferably near the repair area. Stored in bulk asfaltogranulate roadside has a negative impact on the environment. Due to the precipitation into the soil, and then the surface water and groundwater contaminants fall asfaltogranulate, such as heavy metals or oil-containing impurities. There is a total or partial destruction of the top soil, there is desertification. Also when unloading, loading and storage in ambient air pollutants get dusty. It can not be ignored, especially if the work is carried out in an urban setting. The Federal classification catalog of waste asphalt crumb relates to 4 (low hazard) class of waste. The ecological system after exposure to asfaltogranulate disturbed ecosystem need three years of self-healing. the storage area should be prepared to meet the requirements for the storage of the material. Nestle waterproof coating, precluding the pollution of soil, canopy to protect the surface of the mound from rain and wind, and the scheme of sewage wastewater.

Keywords: repair of pavement, cold regeneration technology, recycler, road milling machine, asphalt crumb, road-building materials, warehousing, class of danger of waste, waste management, ecology, soil, pollution.

\section{Введение}

Главной экологической проблемой в современном мире является загрязнение окружающей среды промышленными отходами разных отраслей производства [1]. Строительство автомобильной дороги наносит немалый урон природе, оказывая негативное влияние на литосферу, гидросферу, атмосферу и биосферу. Дороги должны быть спроектированы и построены так, чтобы отрицательное воздействие на окружающую среду было минимальным [2].

Совсем недавно появилась технология холодной регенерации дорожных покрытий [3]. Этот метод «переукладки» дорог позволяет вторично использовать материалы старой дорожной одежды, исключив надобность требуемой утилизации для асфальтобетона. Асфальтогранулят - это материал, получаемый в результате фрезерования асфальтобетонного покрытия. Асфальтовую крошку применяют для устройства оснований и покрытий дорожных одежд автомобильных дорог III категории и ниже и соответствующих им категорий городских улиц и дорог, а также укрепления обочин, откосов $[4,5]$. При выполнении ремонта дороги иногда возникает необходимость временного складирования асфальтовой крошки.

\section{1. Класс опасности отходов асфальтогранулята}

На территории России действует Федеральный классификационный каталог отходов (ФККО) (с 1 августа 2014 г., с изменениями от 3 июня 2016 г.), который разделяет отходы по происхождению, агрегатному состоянию и опасности. 
В настоящее время в России для отходов в соответствии с приказом Министерства природных ресурсов РФ от 15.06.2001 г. № 511 установлено пять классов опасности:

- I класс (чрезвычайно опасные);

- II класс (высокоопасные);

- III класс (умеренно опасные);

- IV класс (малоопасные);

- V класс (практически неопасные).

В ФККО под кодом 83020001714 записан вид отходов «Лом асфальтовых и асфальтобетонных покрытий», к которому относится асфальтогранулят. Класс опасности - IV . Особенности данного класса отхода указаны в таблице.

Особенности асфальтогранулята как вида отходов

\begin{tabular}{|c|c|c|}
\hline $\begin{array}{c}\text { Класс опасности } \\
\text { отода для окружающей } \\
\text { природной среды }\end{array}$ & $\begin{array}{c}\text { Степень вредного } \\
\text { воздействия опасных } \\
\text { отхдов на окружающую } \\
\text { природную среду }\end{array}$ & $\begin{array}{c}\text { Критерии отнесения опасных } \\
\text { отходов к классу опасности } \\
\text { для окружающей природной } \\
\text { среды }\end{array}$ \\
\hline $\begin{array}{c}\text { IV класс } \\
\text { (малоопасные) }\end{array}$ & Низкая & $\begin{array}{c}\text { Экологическая система нару- } \\
\text { шена, период самовосстанов- } \\
\text { ления - не менее 3 лет }\end{array}$ \\
\hline
\end{tabular}

Согласно Санитарно-эпидемиологическим правилам и нормативам СанПиН 2.1.7.1322-03 «Гигиенические требования к размещению и обезвреживанию отходов производства и потребления» (утв. Главным государственным санитарным врачом РФ 30 апреля 2003 г.) условия временного складирования определяются классом опасности отходов и записываются в техническом регламенте (проекте) в зависимости от агрегатного состояния. В IV класс входят нефтесодержащие отходы, способные в корне изменить физико-химические свойства почвы [6]. Далее последуют загрязнение подземных вод и уничтожение биосферы на данной территории. В связи с этим необходимо полностью исключить контактное воздействие асфальтогранулята с почвенным покровом. Хранение твердых отходов асфальтобетонного покрытия разрешается на открытых площадках с твердым водонепроницаемым покрытием в виде насыпи [7].

В п. 3.7 СанПиН 2.1.7.1322-03 перечислены условия при временном хранении материалов на открытых складах:

- временные склады и открытые площадки должны располагаться с подветренной стороны по отношению к жилой застройке; 
- поверхность хранящихся в виде насыпи отходов должна быть защищена от воздействия атмосферных осадков и ветров (укрытие брезентом, оборудование навесом и т.д.);

- поверхность площадки должна иметь искусственное водонепроницаемое и химически стойкое покрытие (асфальт, керамзитобетон, полимербетон, керамическая плитка и др.);

- по периметру площадки должны быть предусмотрены обваловка и обособленная сеть ливнестоков с автономными очистными сооружениями;

- поступление загрязненного ливнестока с этой площадки в общегородскую систему дождевой канализации или сброс в ближайшие водоемы без очистки не допускаются.

Малоопасные отходы могут храниться на территории предприятия или за его территорией в виде специально спланированных отвалов и хранилищ [8].

После окончания строительства или ремонта автомобильной дороги земли, выделяемые для складов дорожно-строительных материалов и подъездных путей, должны рекультивироваться [9]. Обязательно проведение мероприятий по восстановлению плодородных свойств земли.

Не стоит забывать, что декоративное озеленение усиливает связь автомобильной дороги с окружающей природной средой [10]. Главное не только посадка новых кустарников и деревьев, но и сохранение существующей растительности, дополнение новыми посадками, вписывающихся в ландшафт или маскирующих непривлекательные места [11].

\section{2. Данные наблюдения за площадкой временного складирования асфальтогранулята}

Объектом наблюдения является площадка (территория) вблизи отремонтированного участка дороги, которая ранее использовалась для временного складирования асфальтогранулята (данные о подрядной организации и участке дороги конфиденциальны). Перед подрядчиком стояла задача замены дорожного полотна методом холодной регенерации. Работы по ремонту завершились в срок, качественно, все решения по выбору технологий обоснованы. Однако подрядчик, используя метод фрезерования асфальта, не учел требования для размещения (складирования) асфальтогранулята (рис. 1). 


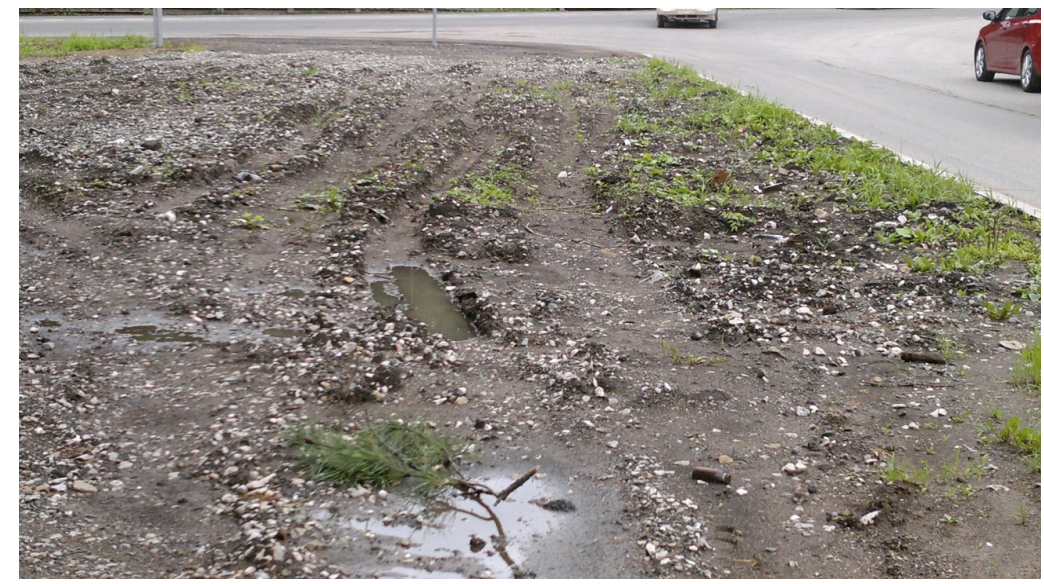

Рис. 1. Место «временного хранения» асфальтогранулята после завершения работ

Легко определяется место, где производилось складирование отфрезерованного асфальта при ремонте дороги. Не выполнялись правила хранения отхода IV класса опасности для экосистемы. На временной площадке для хранения материала не использовалось водонепроницаемое покрытие, которое могло бы предотвратить попадание загрязняющих веществ в подземные водные источники. Насыпь располагалась непосредственно на не защищенной от воздействия данного отхода почве. Невооруженным глазом видно, что нарушен растительный слой. Происходит деградация почвенного покрова, ухудшаются свойства почвообразования [12]. В почвенные слои могут проникать загрязняющие вещества, такие как нефтепродукты и тяжелые металлы, при продолжительных атмосферных осадках и несоблюдении требуемого отвода ливневых вод с площадки [13]. Следствием этого могут быть опустынивание земель, снижение плодородия (рис. 2). Еще одним явным признаком нарушения экосистемы территории для складирования материала является частичное заболачивание, появление небольших зон затопления. Отмечаются механические повреждения почвенного покрова вследствие передвижения транспорта и строительной техники в период производства работ. Исходя из этого, делаем вывод о загрязнении плодородного слоя горюче-смазочными материалами.

Складирование асфальтогранулята располагается близко к жилой застройке. Во время ремонтных работ отсутствовал навес над насыпью. Дождевая вода с примесью просачивается в плодородный слой почвы, изменяя физико-химические свойства почвенного покрова, за- 
тем попадает в грунтовые воды. Однозначно, этот участок не был специально подготовленным для складирования асфальтовой крошки. После завершения работ материал полностью не вывезен в специально отведенные места для утилизации, остатки асфальтогранулята остались на придорожной полосе.

Спустя год экологическая ситуация данного участка не изменилась. Остатки асфальтогранулята уплотнились под действием климатических факторов. Площадка, которая предназначалась для складирования асфальтогранулята, на сегодняшний день используется пешеходами как ближайший путь до остановки. Почва за год не восстановила свои плодородные свойства, участок не зарастает травой и мелким кустарником (рис. 3).

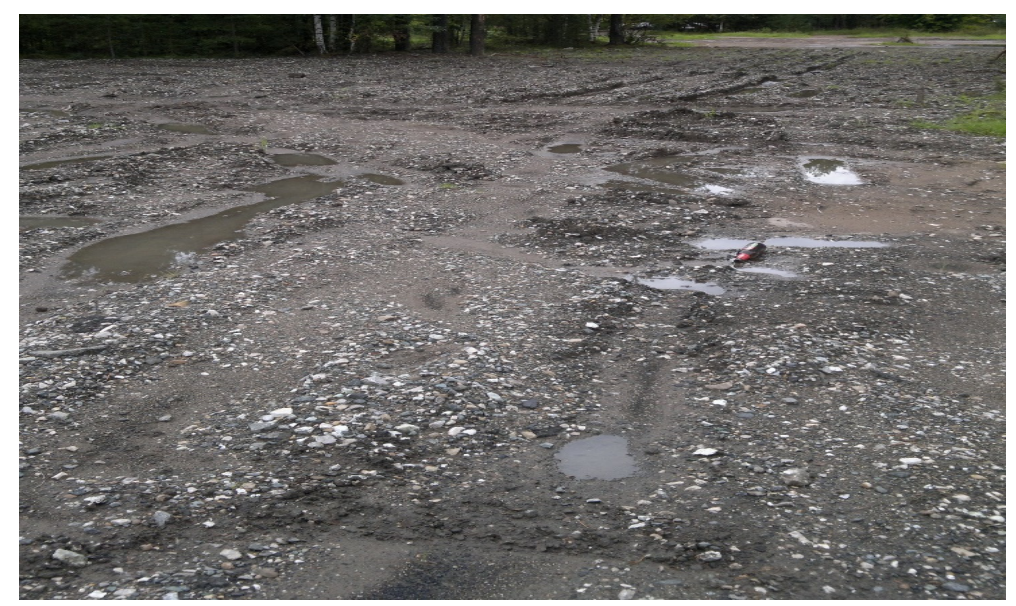

Рис. 2. Опустывание участка

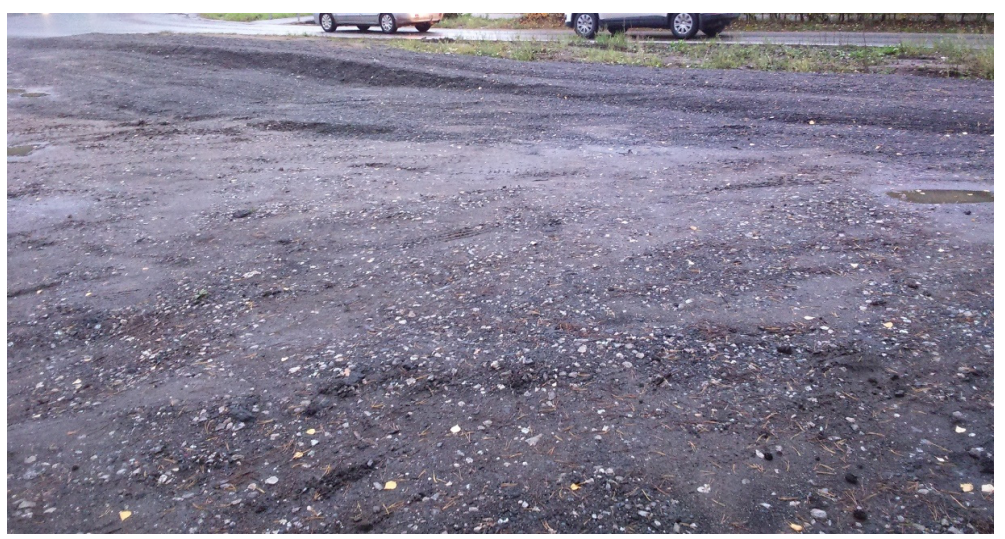

Рис. 3. Состояние участка через год после ремонта дороги 
Замечена специально уложенная дорожка, предположительно из асфальтогранулята (рис. 4).

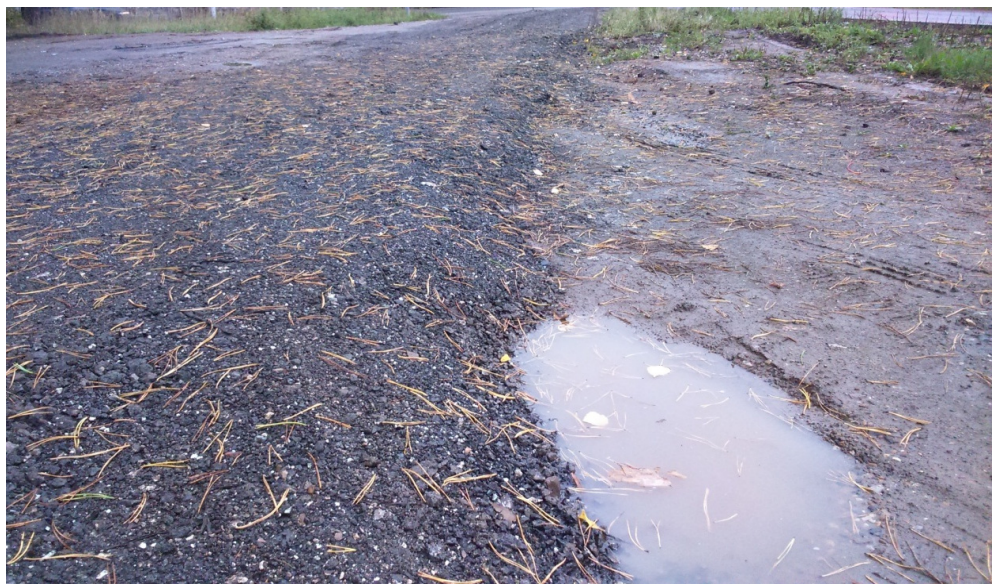

Рис. 4. Дорожка из асфатогранулята

Автомобильные дороги относятся к такому виду сооружений, которые оказывают негативное влияние на окружающую среду [14]. При их строительстве отводятся большие площади для вырубки древесной и кустарниковой растительности, загрязняются водоемы, нарушаются физикомеханические свойства почв. В результате нарушается баланс экосистемы прилегающей природной территории. Главная цель производства работ по строительству и ремонту автомобильных дорог заключается в понимании экологической проблемы и выборе необходимых мероприятий по охране окружающей среды, чтобы не допустить негативного воздействия производственной деятельности на природу [15].

\section{Заключение}

Экологическая проблема, рассматриваемая в данной статье, - это складирование асфальтогранулята и его влияние на почвенный покров. Наблюдения за участком в течении двух лет и анализ данного материала как вида отходов доказали, что складирование дорожно-строительных материалов нуждается в особом внимании. Экосистема наблюдаемой территории нарушена вследствие складирования на ней асфальтогранулята. Действительно, отмечаются нарушение плодородных свойств почвы, отсутствие растительности и частичное затопление наблюдаемой местности. 
В современном мире часто не выполняются работы, связанные с охраной окружающей среды. Люди пренебрегают требованиями при временном складировании и утилизации отходов. Выбросы вредных веществ в атмосферу превышают допустимые значения. Наблюдается пренебрежительное отношение к рекультивации земель и др. Необходимо стараться уменьшать меру воздействия объекта (либо автомобильной дороги в целом, либо дорожно-строительного материала в частности) на окружающую среду. Нужно также принимать меры по предотвращению негативного влияния дорожного хозяйства на природу.

\section{Список литературы}

1. Мазур И.И., Молдаванов О.И. Курс инженерной экологии: учеб. для вузов / под ред. И.И. Мазура. - 2-е изд., испр. и доп. - М.: Высш. шк., 2001. - 510 с.

2. Платонов А.П., Моисеев И.В. Автомобильные дороги и охрана природной среды: учеб. пособие / Иван. инж.-строит. ин-т. - Иваново, 1993. - $146 \mathrm{c}$.

3. Цепенников А.А., Кузнецов В.Ю. Метод холодной регенерации как способ использования материалов старых асфальтобетонных покрытий при реконструкции и капитальном ремонте // Проблемы проектирования, строительства и эксплуатации автомобильных дорог. Охрана окружающей среды: материалы III Всерос. науч.-техн. конф. молодых ученых, аспирантов и студентов, Пермь, 21-22 апреля 2005 г. / Перм. гос. техн. ун-т. - Пермь, 2005. - С. 284-288.

4. Семенов С.С., Кузнецов В.Ю. Применение асфальтогранулобетона в дорожном строительстве // Перспективы развития инноваций в энергоресурсосбережении: материалы Bсерос. науч.-практ. конф. с междунар. участием, Пермь, 16-18 декабря 2007 г. - Пермь: Изд-во Перм. гос. техн. ун-та, 2008. - С. 268-274.

5. Дорожно-строительные материалы: учеб. для автомоб.-дорож. ин-тов / И.М. Грушко [и др.]. - М.: Транспорт, 1983. - 383 с.

6. Управление отходами. Полигонные технологии захоронения твердых бытовых отходов. Рекультивация и постэксплуатационное обслуживание полигона: монография / Я.И. Вайсман [и др.]; под ред. Я.И. Вайсмана. - Пермь: Изд-во Перм. нац. исслед. политехн. ун-та, 2012. - 243 c.

7. Строкин И.И. Перевозка и складирование строительных материалов: справ. строителя. - М.: Стройиздат, 1994. - 463 с. 
8. Охрана окружающей природной среды при проектировании и строительстве автомобильных дорог: учеб. пособие / М.В. Немчинов [и др.]. - М.: Изд-во Ассоциации строительных вузов, 2009. - 280 с.

9. Аксенов И.Я., Аксенов В.И. Транспорт и охрана окружающей среды. - М.: Транспорт, 1986. - 176 с.

10. Содержание городских улиц и дорог: справ. / 3.И. Александровская [и др.]. - М.: Стройиздат, 1989. - 208 с.

11. Строительство дорожных одежд, тротуаров, дорожек и автомобильных стоянок / А.Я. Тулаев [и др.]. - М.: Стройиздат, 1988. - 367 с.

12. Инженерная экология и экологический менеджмент: учеб. / М.В. Буторина [и др.] / под ред. Н.И. Иванова, И.М. Фадина. - М.: Логос, 2004. - $520 \mathrm{c}$.

13. Инженерная экология: учеб. / под ред. В.Т. Медведева. - М.: Гардарики, 2002. - 687 с.

14. Орнатский Н.П. Автомобильные дороги и охрана природы. М.: Транспорт, 1982. - 176 с.

15. Луканин В.Н., Трофименко Ю.В. Промышленно-транспортная экология: учеб. для вузов / под ред. В.Н. Луканина. - М.: Высш. шк., 2003. - 273 c.

\section{References}

1. M azur I.I., M oldavanov O.I. K urs inzhenernoi ekologii [Environmental engineering course]. M oscow: V ysshaia shkola, 2001. $510 \mathrm{p}$.

2. Platonov A.P., M oiseev I.V. A vtomobil'nye dorogi i okhrana prirodnoi sredy [Highways and protection of the natural environment]. Ivanovo: Ivanovskii inzhenerno-stroitel'nyi institut, 1993. 146 p.

3. Tsepennikov A.A., Kuznetsov Iu.V. M etod kholodnoi regeneratsii kak sposob ispol'zovaniia materialov starykh asfal'tobetonnykh pokrytii pri rekonstruktsii i kapital'nom remonte [Cold regeneration method as a way to use the materials of the old asphalt concrete pavement during reconstruction and overhaul]. Materialy III Vserossiiskoi nauchno-tekhnicheskoi konferentsii molodykh uchenykh, aspirantov $i$ studentov "Problemy proektirovaniia, stroitel'stva i ekspluatatsii avtomobil'nykh dorog. Okhrana okruzhaiushchei sredy”, Perm, 21-22 April 2005 goda. Perm': Permskii gosudarstvennyi tekhnicheskii universitet, 2005, pp. 284-288.

4. Semenov S.S., K uznetsov V.I u. Primenenie asfal 'togranul obetona v dorozhnom stroitel'stve [Application of asphalt granule concrete in road construction]. Materialy Vserossiiskoi nauchno-prakticheskoi konferentsii s 
mezhdunarodnym uchastiem "Perspektivy razvitiia innovatsii $v$ energoresursosberezhenii”, Perm', 16-18 December 2007 goda. Perm': Permskii gosudarstvennyi tekhnicheskii universitet, 2008, pp. 268-274.

5. Grushko I.M. [et al.]. Dorozhno-stroitel'nye materialy [Road construction materials]. M oscow: Transport, 1983. $383 \mathrm{p}$.

6. Vaisman Ia.l. [et al.]. Upravlenie otkhodami. Poligonnye tekhnologii zakhoroneniia tverdykh bytovykh otkhodov. Rekul'tivatsiia i postekspluatatsionnoe obsluzhivanie poligona [W aste management. Landfill technologies of disposal of solid waste. Reclamation and post-operational maintenance of the landfill]. Perm': Permskii natsional'nyi issledovatel'skii politekhnicheskii universitet, 2012. 243 p.

7. Strokin I.I. Perevozka i skladirovanie stroitel'nykh materialov [Transportation and storage of building materials]. Moscow: Stroiizdat, 1994. $463 \mathrm{p}$.

8. Nemchinov M.V. [et al.]. Okhrana okruzhaiushchei prirodnoi sredy pri proektirovanii i stroitel'stve avtomobil'nykh dorog [Protection of the natural environment in the design and construction of roads]. M oscow: Izdatel'stvo A ssotsiatsii stroitel'nykh vuzov, 2009. 280 p.

9. A ksenov I.Ia., A ksenov V.I. Transport i okhrana okruzhaiushchei sredy [Transport and environmental protection]. M oscow: Transport, 1986. $176 \mathrm{p}$.

10. A leksandrovskaia Z.I. [et al.]. Soderzhanie gorodskikh ulits i dorog [Contents of city streets and roads]. M oscow: Stroiizdat, 1989. 208 p.

11. Tulaev A.la. [et al.]. Stroitel'stvo ulits i gorodskikh dorog [Construction of pavements, sidewalks, paths and car parks]. M oscow: Stroiizdat, 1988. $367 \mathrm{p}$.

12. Butorina M.V. [et al.]. Inzhenernaia ekologiia i ekologicheskii menedzhment [Engineering ecology and environmental management]. M oscow: Logos, 2004. 520 p.

13. Medvedeva V.T. Inzhenernaia ekologiia [Engineering ecology]. M oscow: Gardariki, 2002. 687 p.

14. Ornatskii N.P. A vtomobil'nye dorogi i okhrana prirody [Highways and Environmental Protection]. M oscow: Transport, 1982. 176 p.

15. L ukanin V .N., Trofimenko I u.V. Promyshlenno-transportnaia ekologiia [Industrial and transport environment]. Moscow: Vysshaia shkola, 2003. $273 p$.

Получено 10.11.2016 


\section{Об авторах}

Весникова Анастасия Владиславовна (Пермь, Россия) - магистрант кафедры «Автомобильные дороги и мосты», Пермский национальный исследовательский политехнический университет (614013, г. Пермь, ул. Академика Королева, 19a, e-mail: vesnikovaav@ mail.ru).

Бургонутдинов Альберт Масугутович (Пермь, Россия) - кандидат технических наук, доцент, доцент кафедры «Автомобильные дороги и мосты», Пермский национальный исследовательский политехнический университет (614013, г. Пермь, ул. Академика Королева, 19a, e-mail: burgonutdinov.al bert@yandex.ru).

Ожигин Павел Сергеевич (Пермь, Россия) - старший преподаватель, Пермский военный институт войск национальной гвардии Российской Федерации (614112, г. Пермь, ул. Гремячий Лог, 1, e-mail: ps_ozhigin@mail.ru).

\section{About the authors}

Anastasiia V. Vesnikova (Perm, Russian Federation) - M aster Student, M otor Roads and Bridges Department, Perm National Research Polytechnic University (19a, A cademician Korolev st., Perm, 614013, Russian Federation, e-mail: vesnikovaav@mail.ru).

Al'bert M. Burgonutdinov (Perm, Russian Federation) - Ph.D. in Technical Sciences, A ssociate Professor, M otor Roads and Bridges Department, Perm National Research Polytechnic University (19a, A cademician K orolev st., Perm, 614013, Russian Federation, e-mail: burgonutdinov.al bert@ yandex.ru).

Pavel S. Ozhigin (Perm, R ussian Federation) - Senior Lecturer, Perm Military Institute of the National Guard Troops of the Russian Federation (1, Gremiachii Log st., Perm, 614112, Russian Federation, e-mail: ps_ozhigin@mail.ru). 